\title{
Critiquing Recalling as Mechanism in Answering Questions during Evaluation
}

\author{
Kenneth Bright Boateng \\ Department of Fashion \\ Design \\ Takoradi Polytechnic \\ Takoradi, Ghana
}

\author{
John Frank Eshun \\ Department of Interior \\ Design and Technology \\ Takoradi Polytechnic \\ Takoradi, Ghana
}

\author{
Frederick Boakye Yiadom \\ Department of Sculpture \\ Takoradi Polytechnic \\ Takoradi, Ghana
}

\begin{abstract}
Evaluation has been the key measuring instrument employed to determine knowledge, skill, and competence levels in Ghanaian schools. By design, conventional assessment has been structured for students to recall studied materials and re-produce it through oral presentation, inscription, and/or demonstration. This is also the orthodox order by which appraisal has been undertaken to declare pass and qualification. The mechanism by which performance, knowledge, skill, and competence are determined based on volume of information to recall appears to be a limiting factor in measuring knowledge, skill, and competence especially in Technical and Vocational Education Training (TVET). Relatively, it is a common feature in world of work where labour has the leverage to refer from documented materials and other authorities and experts to deliver as expected. The study thus, is an inquiry attempting to look into the means of measuring performance, knowledge, skill, competence, and standards without depending much on absolute recall. It is a direct attempt to reduce rote learning drastically and prepare students for life other than examination. Being literally qualitative and quasi-experimental research, the inquest will adopt observation, descriptive, interpretative, and partial experimental research.
\end{abstract}

Keywords: Evaluation, Student, Teacher, Recall, and Learning.

\section{INTRODUCTION}

Many an authority of education will describe education as a means by which people who enroll (students) into school could be trained and guided to acquire knowledge, skill, and competence (Smith, 2015, Roni, 2011, \& Tesha, 2016). By design, education also imbibes and sharpens the capacity into being adaptive and poised physically, mentally, emotionally, fit, and responsible (Smith, 2015, Roni, 2011, $\&$ Tesha, 2016). To declare the student who must have gone through the system passed well enough to exit the confines of the school, the former ought to have proved that all learning outcomes espoused must have been acquired reasonably and evaluation is the key yardstick for undertaking search measurement. Since the inception of formal education, summative assessment has been the key tool by which performance and capacity is determined. Recently, a mix of formative and summative assessments in the ratio 4:6 have been instituted in many institutions in Ghana and that is what Takoradi Polytechnic also adopts. The structure by which these assessments are executed for appraisal have many questions among them is the challenge of volume of information that can be memorized and its relationship with pass, adaptation, and performance which have been encapsulated by Novak, (2011) p. 1., as think, feel, and act. At present, dominance of the concept of thinking (recall) and act (delivery) with limited reference to feel (how or methodology) form the fundamental challenge of illiterate graduate and the reason why employers look for five (5) to ten (10) year working experience.

By and large, qualification has been linked directly to the ability of the student to recall as much as possible and present as directed by the marking scheme in making required grade for transition to the next level. Instinctively, this has introduced varying dynamics into schooling and evaluation and subsequently knowledge, skill, and competence. Passing adequately has been the goal and thus, the conventional practice is to grasp as much as possible, recall, and deliver orally and/or inscriptively. Often, students eagerly ask for notes or pamphlets, study the contents, and deliver on demand. Summarily rote learning has become so entrenched and prevalent defeating grossly the key aims and objectives of education. According to (Mayer, 2002), retention focuses on the past and transfer focuses on the future. Within the context, retention looks at memorizing and transfer requires memorization to deliver in performance. Now, the end is prioritized over the means and as such, many students have been drawn into the penchant of cheating: influencing facilitators and examination 
officials to buy questions and marking schemes, manipulate results, and refer to foreign materials and discussions whiles examination is in session. Ultimately, ill-equipped graduates and professionals get churned out; hence, the emerging phenomenon where industry requires five (5) to ten (10) year working experience before hiring. Industrial players for some time have bemoaned passionately that graduates do not measure up to standards required for the world of work. Correlating with the context is the opine caveat by Novak (2011) p.1., that expresses learners, teachers, subject matter selected, social milieu, and evaluation to be benchmarks of education theory. Indeed, every graduate should have certificate serving as evidence in support of satisfying the benchmarks Novak has advocated. However, direct relationship between evidential certificate and evidential result from productivity is core of the controversy. The sensitive and unfortunate situation is particularly dire in TVET education like the polytechnic where knowledge, skill, and competence are the targets.

Increasing dangers from over-emphasizing skill and competence performance appears to have its associated limitations likewise. To illustrate its effect, Battino, (1992) p. 1., argues that understanding and recalling elements of the periodic table in chemistry is very essential in appreciating technical and technological processes and theories of chemistry. Factually, practical undertakings may be helpful but to assimilate and memorize cannot be ostensibly missing in this endeavour. That is why the contention of meaningful learning by Mayor, (2002) p.1., where convergence is made between the Taxonomy of retention and transfer appears to be on spot. If meaningful is relegated to the background, then brace yourself for any of the three possibilities: no learning, rote learning, and meaningful learning (Mayor, 2002, pp. 12).

The struggle in Ghana points to the trajectory where the focus is on pass to make it to the next level (academic progression and/or world of work). Under the regime of president John Agyekum Kufour, it was believed that making high school duration seven (7) years that is from age 12 to 19 should equip students comprehensively for progression into tertiary notably university. As at now, the then government, Ministry of Education, and Ghana Education Service are yet to produce any scientific evidence to support the claim that increment in volumes that passed West Africa Senior Secondary Certificate Examination (WASSCE) as a result of four (4) year senior high school education had meaningful learning. The damage is revealed in placing emphasis on rote learning to the detriment of meaningful (smart) learning ultimately leading to no learning. A reflection seen when industry provide feedback on performance on students on industrial attachment and internship. We are often told by industry how frequently students from the regular universities use grammar to express and explain issues but struggle to deliver on the job whereas the HND students deliver on the job and also struggle to express themselves freely.

\section{RESEARCH DESIGN}

As a typical applied research, the broadly qualitative study has somewhat worked along quasi-quantitative approach utilizing experimental, observation, descriptive, and interpretative design and method. It has elicited factors that fan recall and rote learning leading to the chaos being experienced and suggest remedies. It is hoped the outcomes will give stronger basis and support for CBT and formative assessment as the paradigm in TVET especially at the Polytechnic.

Employment of qualitative and quasi quantitative approaches are revealed in sessions as facilitators (teachers) and learners get interacted. During sessions, a common experience is to get students ask lecturer to convert the materials into notes even though full references have been provided in support of study material. Students will be sincere to confess regardless of provided references; we did not really consult the reference for information and knowledge expansion. On the contrary, they prefer to get busy during revision and examination period to recall as much as possible. Approach to evaluation particularly: quizzes and examinations has been much disturbing as though the world of the student must have ended. People strive to burn the mid-night oil, try to cheat, and worst of all, unable to apply whatever material they must treated creditably during the quiz or examination in future even with reference materials in support. Most of all, many lecturers do not see the need to limit the application of summative assessment to the advantage of formative assessment: a pattern that became obvious during curricular review in transition from polytechnic to technical university in 2016. And the relevance is seen because many of the lecturers have the same background as the students and would wish to work with convenience. During the end of year examinations which ended in June, 2016, out of eight papers (8) a lecturer invigilated, it was one that seems to have professionally well composed question for the examination. A related very disturbing phenomenon is examination result manipulation by lecturers and in some instances, examination officers. Generally depending on summative assessment puts lecturer in charge and gets students forced to explore but without evidence to support legitimacy of the so called acquired knowledge.

\section{RESULTS AND DISCUSSION}

As part of the inquest for this paper, a quiz was conducted for mid-semester examination and presented for your perusal.

\section{TAKORADI POLYTECHNIC}

\section{MID-SEMESTER EXAMINATION QUESTION}

\begin{tabular}{|cc|}
\hline SCHOOL: Applied Arts & YEAR: HND 1 \\
\hline $\begin{array}{c}\text { DEPARTMENT: Fashion Design and Textile Studies } \\
\text { Semester: Two (2) }\end{array}$ \\
\hline
\end{tabular}




\begin{tabular}{|lr|}
\hline $\begin{array}{l}\text { PROGRAM: Fashion Design and } \\
\text { Section: 2015/16 }\end{array}$ & Textile Studies \\
\hline $\begin{array}{l}\text { COURSE: Drawing } \\
\text { Illustration }\end{array}$ & and \\
Course Code: FDT 106 & \\
\hline Duration: 1 1/2 Hours & Credit Hours: 3 \\
\hline $\begin{array}{l}\text { NAME OF LECTURERS: Kenneth Bright Boateng } \\
\text { and Ahmed Jibril }\end{array}$ & \\
\hline
\end{tabular}

\section{INSTRUCTIONS}

You are permitted to come in with all your reference materials with the exception of computers and smart phones. Also come along with relevant drawing and painting materials and instruments. Answer all questions

1. State and explain the main relevance why in illustrations, the legs are portrayed to look taller than the torso/trunk in fashion.

5 Marks

2. List five (5) elements of design and show how to demonstrate each visibly in garments and accessories with two (2) points each.

10 Marks

3. Identify with two (2) points each how colour illusion can be used for the following:

a) Increase girth of an extreme slim silhouette

b) Reduce height of a very tall person

10 Marks

4. State two (2) ways by which you can adopt balance to reduce a protruding waist of a lady conveniently.

5 Marks

5. State and explain with two (2) points on how to apply occasion and function in bridal apparel. Support your answer with credible examples.

10 Marks

The findings from the examination have been treated as follows:

Pedagogy and andagogy are key training doctrines which aid directing learning form known to the unknown; simple to complex; concrete to abstract. Virtual skill required to express little or much vividly for the understanding of students is a teaching artistry that requires observation, experience, and versatility. Knowledge and use of these principles does depend on age but capacity of the learner and hence, the difficulty in its application during training of disengaged students as pertain in the polytechnic. Looking at average age students in the polytechnic makes it easier to conclude that they are matured which is highly subjective. Understandably, dependent on formative assessment brings knowledge, skill, competence, and adaptive cleverness (versatility) but the former is inadequate that is why the significance of summative assessment cannot be overemphasized. Granting documented materials to facilitate revision and personal studies are not evil but needs to be highly skewed to reflect capacity and strength of student to stimulate personal drive for quality knowledge, skill, and competence. Of the nine (9) students whose project report were vetted in 2015/2016 academic year, only one had good command over oral and written English. Seven (7) were not impressive but two (2) could not write a complete sentence with grammatical flaws even though they have adequately delivered the final collection (end of programme project work).

Absenteeism and truancy is a regular feature in training institutions across education with teachers and educational authorities employing varying tools for its control. To root out this debilitating quagmire, trainers and institutions may want to consider alternative motivation where no documented material in the form of notes, pamphlets, leaflets, and handouts are issued to students but the latter is required to deliver answers to smart quiz within $30 \mathrm{~min}$ at the beginning of first session of every month. From observation, many smart students of very large class size stay out of attention and sneak in and out of class at will but make the required grades all the time. Varying the rules of engagement to demand performance through direct contact as seen in formative assessment should literally reduce this menace of education.

In the past, a regular practice in evaluation is to offer mark up for brilliant performance but it was discovered that this simply became another avenue for teachers to hand over marks freely to their favorites spanning from the welldressed, athletes, disciplined, child with special needs, errand runners, and even concubines. A more scaring phenomenon is where teachers load questions requiring voluminous written statements that the former would not have the time to mark and award appropriate marks. In short, the teacher just awards marks based on familiarity and fraternity other than performance. The compelling evidence is so staggering knowing that some failures and excellence do not necessarily merit the award with its subsequent tag.

Note taking, pamphlets, leaflets, and handouts have additionally problems creating tremendous challenges to education authorities and the more allowed to thrive, the worse. The problems become apparent just at the beginning of the semester where it takes three (3) weeks or more for average regular student to report fully for lectures even though only the first week is required for registration. They walk casually into class late and then sit oblivious of their environment chatting, fondling their smart phones, and/or absent minded. 'Anyway, I will get the notes from a friend to prepare for the examinations' - that is feedback when questioned. Albeit offensive, reading into it should reveal a structural problem arising from teachers and institutional authorities. If it is permissible for students to be compelled to buy handouts, leaflets, and pamphlets with some attaching award of points and marks to it, you could not be asking for a lesser trouble. This practice reduces discipline and makes 
the vulnerable susceptible to abuse by fellow students and in some cases, teachers and education authorities.

The importance of rote learning is being stretched beyond reason and many a teacher has not seen it to be a time bomb. As illustrated by local parlance in Ghana: 'chew, pass, and forget'; many a student goes through great length to grasp and assimilate as much as possible. Trying to capture and memorize contents is not adequate to guarantee productivity is a challenge because that has been their experience from the basic levels. At the polytechnic where beyond completion of programme is on the job performance requires additional skill and competence that can and must convert raw or semi-finish to finish. Well, some teachers contend that well designed questions from open ended to close ended within the context of knowledge, skill, and competence demonstrated by the learning outcome should draw appropriate responses from the answers students provide. But, a counter contention is the student has recalled and provided the answers as being demanded but cannot perform the task in the world of work.

Since 1993 when I began practicing professional teaching from basic through secondary to tertiary, am yet to experience examination (spanning from invigilation to awards) where cheating (copying from neighbours and friends; foreign materials; discussion; spying; omission and/or manipulation of results, by students and/or personnel) never occurred. Spying appears to be the commonest where students attempt to steal glances at the work of neighbours. No mean lesser, another regular occurrence is the penchant to talk and talking whiles examination is in session. Albeit it seldom happens, some students have the boldness to grab others works (exchange) and copy oblivious of the presence of invigilator. But the worst and bizarre are smuggling of foreign materials into the examination and then manipulation of and/or by personnel and results. Even at the highest (tertiary) level, I have seen students copy on all sort of materials from papers, underwear, skin to sanitary towels and more all in attempt to recall as much as possible without working for it. Some leave the material in quite close proximity to the examination centre (e.g. toilet) and briefly visit to spy. The most disturbing ones are trading of questions, marking schemes, and results by teachers and/or students alike with sex, money, and opportunities not to talk about lazy teachers who manufacture marks and distribute by acquaintance without necessarily reading scripts. The bottom line is the immaculate drive to manipulate the system to secure advantage without working for it. Sanctions for found cases can be very severe ranging from failure of the paper through rustication to outright dismissal but the prognosis appear frankly bleak: the phenomenon does not appear to be halting as in every examination I helped to conduct during my tenures as examination coordinator and chief invigilator, these infractions occurred across all programmes run by the polytechnic.
Anxiety and violence have also crept into the stream of examination. Visibly stressed students who appear broadly worried and exhausted begin to pester teachers and examiners. "What are the questions about? Any possible areas to emphasize in our learning"? In the extreme students get to the wit end and act carelessly. Some try to trade anything for questions, marking schemes, and better results. Others get abused by teachers, examination staff, and fellow students and in the process, people get breakdown. In University of Education in Ghana where mostly advanced age learners enroll most of whom are teachers, students get rushed to hospital during revision and examination period often on worsening heart conditions. In the polytechnic where youthfulness is prevalent, depression is very common. Also common is violence where students attempt to attack fellow students who do not compromise examination sanity. Vigilant and strict invigilators are seen mean and are sometimes attacked verbally. In an incident I witness, a semester six (6) student caught copying from foreign material in his last paper for the examinations which also to complete his HND education decided to wrestle the foreign materials from the two invigilators who accosted him and the seen was very pitiful.

\section{CONCLUSION}

i. Adaptive cleverness by which circumstances could contextualized for sustained optimal performance is extremely essential.

ii. Relevance of knowledge retention from training is revealed in transfer: application of knowledge in adaptation to evolving trends.

iii. Session plan, facilitation, and assessment may require review for adaptation to the trends of the times.

iv. Practical oriented questions with the right for reference from study materials during examination may be helpful after all. In surgical cases, surgeons do not absolutely rely on recall to conduct operations. They sometimes refer to notes and discuss for alternative opinions and/or affirmation.

V. Timely feedback associated with appropriate counseling to those perceived to have challenges during sessions and assessment as the semester wears on could engender better preparation and confidence during examination.

\section{REFERENCES}

[1] Battino, R., (1992). On the importance of learning, p. 1., Provocative opinion. www.pubs.acs.org/doi/pdf/10.1021/ed069p135 Retrieved: May 30, 2016, 02:47hrs.gmt.

[2] Novak, J. D. (2011). A theory of education: meaningful learning underlies the constructive integration of thinking, feeling, and acting leading to empowerment for commitment and responsibility, p. 1., Florida institute for human and machine cognition. 
International Journal of Science and Engineering Applications Volume 5 Issue 7, 2016, ISSN-2319-7560 (Online)

www.ihmc.us/groups/jnovak/ - Retrieved: May 30, 2016, 02:47hrs.gmt.

[3] Mayer, R. E. (2002).

[4] Mayer, R. E. (2002). Rote versus meaningful learning, pp. $1-2$. mit.edu/jrankin/www/teach_transfer/rote_v_meaning. pdf - Retrieved: May 29, 2016, 19:40hrs.gmt.]

[5] Roni, S. H. (2011). Definition of education by the expert http://lapazinaction.blogspot.com/2011/12/definitionof-education-by-expert-2.html - Retrieved: May 29, 2016, 17:40hrs.gmt.]

[6] Smith, M. K. (2015). What is education? A definition and discussion. The encyclopaedia of informal education. http://infed.org/mobi/what-is-education-adefinition-and-discussion/. - Retrieved: May 29, 2016, 11:49hrs.gmt.

[7] Tesha, J. (2016). Plato's concept of education, Introduction.

http://www.sdsmorogoro.com/common/my\%20pages/ research\%20papers/plato's\%20concept $\% 20$ of\%20educ ation.html - Retrieved: May 29, 2016, 17:49hrs.gmt. 